\title{
Synthesis and property of polymer nanospheres with Pd/P4VP shells via surface RAFT polymerization
}

\author{
S. P. Shi, L. F. Zhang, J. Zhu, W. Zhang, Z. P. Cheng*, X. L. Zhu \\ Key Lab. of Organic Synthesis of Jiangsu Province, College of Chemistry, Chemical Engineering and Materials Science, \\ Soochow (Suzhou) University, 199 Renai Road, Suzhou 215123, China
}

Received 27 February 2009; accepted in revised form 14 April 2009

\begin{abstract}
A reversible addition-fragmentation chain transfer (RAFT) agent with carbazole as Z-group was immobilized on the surfaces of the cross-linked poly (4-vinylbenzyl chloride-co-styrene) (PVBCS) nanospheres with a diameter of about $70 \mathrm{~nm}$ by the reaction of benzyl chloride groups in the PVBCS between carbazole and carbon sulfide. Then surface RAFT polymerization of 4-vinylpyridine (4VP) was used to modify the nanospheres to produce a well-defined and covalently tethered P4VP shell. By surface activation in a $\mathrm{PdCl}_{2}$ solution and then reduction by hydrazine hydrate $\left(\mathrm{N}_{2} \mathrm{H}_{4} \cdot \mathrm{H}_{2} \mathrm{O}\right)$, the P4VP composite shells were obtained containing densely palladium metal nanoparticles. The chemical composition of the nanosphere surfaces at various stages of the surface modification was characterized by X-ray photoelectron spectroscopy (XPS). Transmission electron microscopy (TEM) was used to characterize the morphology of the hybrid nanospheres. The $\mathrm{Pd} / \mathrm{P} 4 \mathrm{VP}$ shell nanospheres were also applied to the catalytic reaction and proved to be efficient and reusable for the Heck reaction.
\end{abstract}

Keywords: polymer composites, RAFT polymerization, palladium catalyst

\section{Introduction}

Organic/inorganic hybrid nanoparticles have attracted much attention due to their fascinating optical, electronic, magnetic, photoelectric, biocompatible, and catalytic properties [1-3]. Among the hybrid materials, core-shell nanospheres usually consist of polymer shells and inorganic cores. The organic polymer shell mainly determines the chemical properties of nanoparticles, while the physical properties of nanoparticles are governed by both the size and shape of inorganic cores. There have been a number of methods to prepare coreshell nanospheres with different sizes, structures and compositions, such as sol-gel process [4], layer-by-layer assembly [5], encapsulation of different nanoparticles in cross-linked shell [6] and so on $[7,8]$. Recently, rapid progress in the field of controlled/living radical polymerizations [9-11] has paved the way to prepare well-defined coreshell nanospheres by grafting the polymer chains to the solid nanoparticles [12-14]. Among the major controlled polymerization strategies developed, reversible addition-fragmentation chain transfer (RAFT) [11] polymerization has become one of the most promising techniques to prepare polymer grafted solid supports because this technique can adapt to a wide range of reaction conditions, provides a procedure for the simple preparation of various of block copolymers, and has the compatibility with a wide range of functional monomers [15-17]. Until now, RAFT polymerization has been successfully utilized to graft various polymeric chains onto solid supports to form core-shell systems such as functionalized silica particles [18], gold nano- 
particles [19], CdSe nonaparticles [20], carbon nanotubes [21], Merrifield resins [22] and silica wafers [23]. Recent progress in this field also involves the preparation of hybrid nanoparticles coated with functional polymer brushes [24-26]. For example, Nishi and Kobatake prepared gold nanoparticles covered with photochromic diarylethene polymer that expressed a bright red color via RAFT polymerization [25]. However, there have been few reports on procedures to graft functional polymer chains onto solid supports and the properties, such as catalytic properties, of the shell modified materials.

Palladium is a highly active and selective catalyst in $\mathrm{C}-\mathrm{C}$ bond formation reactions [27-30]. However, the problem that concerns many researchers is to combine high efficiency of the catalyst with the possibility of its easy separation from the reaction products. To the best of our knowledge, the synthesis of palladium (Pd)/polymer nanospheres with core-shell structure via RAFT technique and the investigation of their catalytic properties have not been reported till now. In this work, hybrid nanospheres with a well-dispersed Pd/poly (4vinylpyridine) (P4VP) composite shell and a crosslinked poly (4-vinylbenzyl chloride-co-styrene) (PVBCS) core were prepared via the surfaceRAFT technique. Cross-linked PVBCS nanospheres were synthesized by emulsion copolymerization of 4-vinylbenzyl chloride (VBC) and styrene in the presence of a cross-linking agent, pdivinylbenzene (DVB). The PVBCS nanosphere surfaces were then converted into polymer-supporting RAFT agents by the reaction of the benzyl chloride groups in the PVBCS with carbazole and carbon sulfide. The surface RAFT polymerization of $4 \mathrm{VP}$ produced a well-defined and covalently tethered P4VP shell on the surface of the nanospheres. The Pd/P4VP composite shells were obtained by activating P4VP shells in a $\mathrm{PdCl}_{2}$ solution and then reducing $\mathrm{Pd}^{2+}$ by hydrazine hydrate $\left(\mathrm{N}_{2} \mathrm{H} 4 \cdot \mathrm{H}_{2} \mathrm{O}\right)$. The nanospheres with the Pd/P4VP shells were used as catalysts for the Heck reaction between iodobenzene and methyl acrylate; and the results demonstrated that the catalysts were efficient and reusable for the Heck reaction.

\section{Experimental}

\subsection{Materials}

4-Vinylbenzyl chloride (VBC, 90\%), p-divinylbenzene (DVB, 80\%), iodobenzene (98\%) were supplied by Acros. Styrene (St) and methyl acrylate (MA, analytical reagent, Shanghai Chemical Reagent Co., Ltd, China) were distilled before use. 4-Vinylpyridine (4VP, 95\%) was obtained from Acros, distilled under reduced pressure and then stored at $-15^{\circ} \mathrm{C}$. Azobisisobutyronitrile (AIBN, 99\%, Shanghai Chemical Reagent Co., Ltd, China) was recrystallized twice from ethanol. Benzyl bromide (98\%), 2-propanol (analytical reagent), palladium(II) chloride $\left(\mathrm{PdCl}_{2}\right.$, analytical reagent), sodium dodecyl sulfate (SDS, analytical reagent), potassium persulfate (KPS, analytical reagent), triethylamine ( $\mathrm{Et}_{3} \mathrm{~N}$, analytical reagent), carbazole (analytical reagent), carbon disulfide $\left(\mathrm{CS}_{2}\right.$, analytical reagent), hydrazine hydrate $\left(\mathrm{N}_{2} \mathrm{H}_{4} \cdot \mathrm{H}_{2} \mathrm{O}, 50 \%\right)$ and dimethyl sulphoxide (DMSO, analytical reagent) were purchased from Shanghai Chemical Reagent Co., Ltd, China. 2-Propanol was dried with activated molecular sieve (4 $⿱$ ) ). All other reagents were analytical quality reagents and used as received without further purification.

\subsection{Preparation of cross-linked PVBCS nanosphere}

The cross-linked PVBCS nanospheres were prepared by emulsion copolymerization of $\mathrm{VBC}, \mathrm{St}$ and DVB at $65^{\circ} \mathrm{C}$, using KPS as an initiator and SDS as a surfactant. About $150 \mathrm{mg}$ of SDS was dissolved in $75 \mathrm{ml}$ of deionized water. The monomers, VBC (1.5 ml, $9.6 \mathrm{mmol})$, St $(4.0 \mathrm{ml}, 34.8 \mathrm{mmol})$ and DVB (1.5 ml, $9.0 \mathrm{mmol})$ were well-mixed and dropped into the SDS solution under stirring, to give rise to a milky emulsion. Then the emulsion was kept in an ultrasonic bath for $10 \mathrm{~min}$. The above emulsion was then placed in a three-necked round-bottom flask and purged with argon for $30 \mathrm{~min}$. After KPS (50 mg, $0.18 \mathrm{mmol}$ ) was added at room temperature, the reaction mixture was kept under an argon atmosphere in an oil bath at $65^{\circ} \mathrm{C}$ for $12 \mathrm{~h}$. After polymerization, the PVBCS nanospheres were purified by subjecting them to successive centrifugation/redispersion cycles in deionized water, ethanol, and finally tetrahydrofuran (THF). The obtained nanospheres were dispersed and stored in THF. 


\subsection{Synthesis of chain transfer agent (CTA): benzyl 9H-carbazole-9-carbodithioate (BCBD)}

A suspension of $\mathrm{KOH}(0.24 \mathrm{~g}, 4.2 \mathrm{mmol})$ in DMSO $(20 \mathrm{ml})$ was prepared, and carbazole $(0.71 \mathrm{~g}$, $4.2 \mathrm{mmol}$ ) was added under vigorous stirring. The solution was stirred for $2 \mathrm{~h}$ at room temperature and then carbon sulfide $(0.38 \mathrm{~g}, 5.0 \mathrm{mmol})$ was added dropwise. The resultant reddish red solution was stirred for $5 \mathrm{~h}$ at room temperature, and then benzyl bromide $(0.86 \mathrm{~g}, 5.0 \mathrm{mmol})$ was added. After the mixture was stirred overnight, the mixture was precipitated in a large amount of water, and a yellow solid was obtained. After being recrystallized twice from alcohol, yellow crystals of benzyl 9H-carbazole-9-carbodithioate (BCBD) were obtained. BCBD: Yield: $75 \% .{ }^{1} \mathrm{H}$ NMR $\left(\mathrm{CDCl}_{3}\right): \delta 4.73$ (s, 2H), 7.32-7.47 (m, 9H), 8.00, $7.98(\mathrm{~d}, 2 \mathrm{H}), 8.44$, 8.46 (d, 2H). E EEM. ANAL. Calcd: C $72.03 \%, \mathrm{H}$ $4.53 \%, \mathrm{~N} 4.20 \%, \mathrm{~S} 19.23 \%$; found: C $72.15 \%, \mathrm{H}$ $4.53 \%, \mathrm{~N} 4.18 \%$, S $19.14 \%$.

\subsection{Synthesis of PVBCS supporting chain transfer agent (CTA): PBCBD}

A suspension of potassium hydroxide $(0.24 \mathrm{~g}$, $4.2 \mathrm{mmol})$ in DMSO $(20 \mathrm{ml})$ was prepared, and carbazole ( $0.71 \mathrm{~g}, 4.2 \mathrm{mmol})$ was added under vigorous stirring. The solution was stirred for $2 \mathrm{~h}$ at room temperature and then carbon sulfide $(0.38 \mathrm{~g}$, $5.0 \mathrm{mmol}$ ) was added dropwise. The resultant reddish solution was stirred for $5 \mathrm{~h}$ at room temperature, and then the suspension of the PVBCS nanospheres $(2.0 \mathrm{~g})$ in THF $(50 \mathrm{ml})$ was added. After stirring at room temperature for $36 \mathrm{~h}$, the nanospheres were isolated by centrifugation at $7200 \mathrm{rpm}$, and purified by subjecting them to successive centrifugation/redispersion cycles in THF and finally in 2-propanol. The obtained yellow product, PVBCS supporting RAFT agents (PBCBD), was dispersed and stored in 2-propanol. Elemental analysis: S, $2.41 \%$ (CTA loading: $0.376 \mathrm{mmol} / \mathrm{g}$ PBCBD nanospheres).

\subsection{Synthesis of PVBCS-g-P4VP nanosphere (PVBCS-1)}

In a $25 \mathrm{ml}$ glass tube, $4 \mathrm{VP}(3 \mathrm{ml}, 26 \mathrm{mmol})$, AIBN (2 mg, $0.012 \mathrm{mmol}$ ), 2-propanol (10 ml, containing $0.2 \mathrm{~g}$ PBCBD, 0.074 mmol CTA), and free BCBD
(0.024 g, $0.074 \mathrm{mmol})$ were added. The suspension was dispersed by ultrasonic and then purged with argon for $15 \mathrm{~min}$. Polymerization was carried out under vigorous stirring for a predetermined time at $50^{\circ} \mathrm{C}$. At the end of the polymerization, the surface modified PVBCS-1 nanospheres were purified by subjecting them to successive centrifugation/redispersion cycles in 2-propanol. The final product, PVBCS- $g$-P4VP nanosphere (PVBCS-1), was dispersed and stored in 2-propanol.

\subsection{Preparation of $P d / P 4 V P$ shell nanosphere (PVBCS-2)}

$30 \mathrm{ml}$ of aqueous solution containing $0.1 \mathrm{wt} \%$ $\mathrm{PdCl}_{2}$ and $5 \mathrm{ml}$ of 2-propanol suspension containing $0.1 \mathrm{~g} \mathrm{PVBCS}-1$ were added to a $50 \mathrm{ml}$ glass tube. After stirring for $30 \mathrm{~min}$, the nanospheres were purified by subjecting them to successive centrifugation/redispersion cycles in deionized water. The purified nanospheres were finally dispersed in $20 \mathrm{ml}$ of deionized water. After adjusting $\mathrm{pH}$ to 14 with $1 \mathrm{M} \mathrm{NaOH}$, excess $\mathrm{N}_{2} \mathrm{H}_{4} \cdot \mathrm{H}_{2} \mathrm{O}$ was added to the above suspension. The reaction was carried out at $50^{\circ} \mathrm{C}$ for $1 \mathrm{~h}$ to enable the $\mathrm{Pd}(\mathrm{II})$ to be converted entirely into palladium metal nanoparticles. The nanospheres were purified by subjecting them to successive centrifugation/redispersion cycles in deionized water. The final black product, $\mathrm{Pd} / \mathrm{P} 4 \mathrm{VP}$ shell nanosphere (PVBCS-2), was dried under reduced pressure at room temperature.

\subsection{Heck reaction}

Iodobenzene $(5.0 \mathrm{mmol})$, methyl acrylate (7.5 mmol), triethylamine ( $\left.\mathrm{Et}_{3} \mathrm{~N}, 7.5 \mathrm{mmol}\right), \mathrm{N}, \mathrm{N}$ dimethylformamide (DMF, $20 \mathrm{ml}$ ), and the PVBCS-2 $(15 \mathrm{mg})$ were added into a Schleck flask equipped with a constant temperature oil bath, and the mixture was stirred for $8 \mathrm{~h}$ at $90^{\circ} \mathrm{C}$. After cooling to ambient temperature, the suspension was separated and the precipitate was washed by DMF and diethyl ether. To check its reusability, the precipitate was dried and reused in the next experiment. The filtrate was poured in water $(30 \mathrm{ml})$ and extracted with $\mathrm{CH}_{2} \mathrm{Cl}_{2}(3 \times 20 \mathrm{ml})$. The combined organic phases were dried over $\mathrm{MgSO}_{4}$, filtered and evaporated in vacuum. The products were purified by column chromatography on silica gel using petroleum ether/ethyl acetate $=10: 1(\mathrm{v}: \mathrm{v})$ as eluent . 
${ }^{1} \mathrm{H}$ NMR $\left(\mathrm{CDCl}_{3}\right): \delta 3.81(\mathrm{~s}, 3 \mathrm{H}), 6.43,6.47(\mathrm{~d}$, $1 \mathrm{H}), 7.39(\mathrm{~m}, 3 \mathrm{H}), 7.53(\mathrm{~m}, 2 \mathrm{H}), 7.68,7.72(\mathrm{~d}, 1 \mathrm{H})$. ELEM. ANAL. Calcd: C 74.06\% H 6.21\%; found: C $73.23 \%, 5.97 \%$.

\subsection{Characterizations}

Elemental analysis of $\mathrm{C}, \mathrm{H}, \mathrm{N}$ and $\mathrm{S}$ were measured with an EA1110 instrument. Surface compositions were measured by X-ray photoelectron spectroscopy (XPS). XPS was collected on an XSAM800 spectrometer at a pressure of about $2 \cdot 10^{-8}$ torr using $\mathrm{Mg} \mathrm{K}_{\alpha}$ radiation as the exciting source, which was operated at $12 \mathrm{kV}$ and $11 \mathrm{~mA}$. All binding energies (BEs) were referenced to the $\mathrm{C} 1 \mathrm{~s}$ hydrocarbon peak at $284.6 \mathrm{eV}$. In peak synthesis, the line width (full width at half maximum) of the Gaussian peaks was maintained constant for all components in a particular spectrum. Transmission electron microscopy (TEM) images were recorded on FEI TecnaiG220 transmission electron microscopy at $200 \mathrm{kV}$. The sample was prepared by mounting a drop of the nanosphere dispersion on a carbon-coated $\mathrm{Cu}$ grid, and allowing the sample to dry in air. The atomic absorption spectroscopy (AAS) (Varian Duo-220) was used to determine the percentage of palladium in PVBCS-1 nanospheres. The sample was prepared by removing organic substance in a muffle furnace at $700^{\circ} \mathrm{C}$ and then dissolving in aqua regia. ${ }^{1} \mathrm{H}$ NMR was recorded on an Inova $400 \mathrm{MHz}$ nuclear magnetic resonance instrument with $\mathrm{CDCl}_{3}$ as the solvent and tetramethylsilane (TMS) as the internal standard.

\section{Results and discussion}

\subsection{Synthesis of PVBCS nanosphere with Pd nanoparticle/P4VP composite shells}

Figure 1 shows the synthetic pathway for the preparation of core-crosslinked PVBCS nanospheres with Pd nanoparticle/P4VP composite shells. The process involves (i) preparation of cross-linked PVBCS nanospheres by emulsion copolymerization of VBC and St in the presence of DVB [31], (ii) immobilization of CTA, PBCBD, on the surface of PVBCS nanospheres via reaction of benzyl chloride group in PVBCS nanospheres with carbazole and carbon sulfide [32], (iii) synthesis of PVBCS- $g$-P4VP nanosphere (PVBCS-1) via RAFT polymerization of $4 \mathrm{VP}$, and (iv) preparation of $\mathrm{Pd} / \mathrm{P} 4 \mathrm{VP}$ shell nanosphere (PVBCS-2) via activation with $\mathrm{PdCl}_{2}$ solution and then reduction with $\mathrm{N}_{2} \mathrm{H} 4 \cdot \mathrm{H}_{2} \mathrm{O}$.

Crosslinked PVBCS nanospheres with an average diameter of about $70 \mathrm{~nm}$ were obtained by this method (see later). Subsequently, the key step of this work is to attach RAFT agent to the PVBCS surfaces. In general, the attachment of the RAFT agent to the surfaces of nanoparticles can be accomplished through either the $\mathrm{Z}$ or the $\mathrm{R}$ group $[33,34]$. However, in the R-group approach, where the solid support is a part of the leaving $\mathrm{R}$ groups, higher molecular weight of grafted polymers and grafting density can be achieved [34]. These advantages inspired us to design RAFT agents anchored onto PVBCS nanosphere surfaces through the method of R group moiety. In this work, the benzyl chloride groups on the PVBCS nanosphere surfaces were further reacted with carbazole and carbon sul-
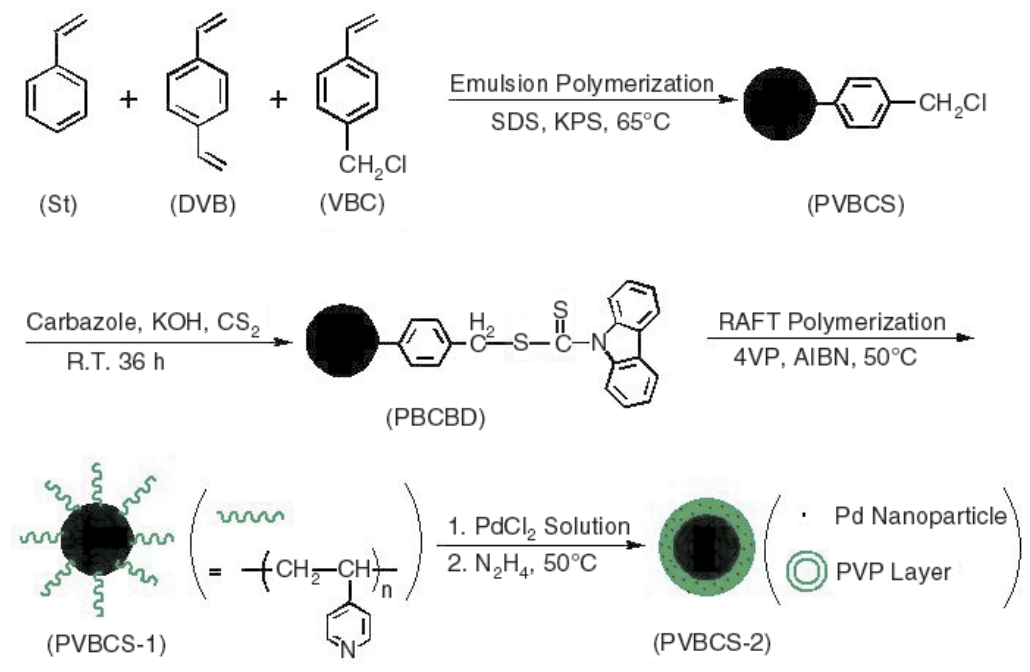

Figure 1. Schematic diagram illustrating the process for the preparation of polymer nanospheres with palladium nanoparticle/P4VP composite shells 
fide, leading to the polymer-supporting chain transfer agent (PBCBD). Elemental analysis of the polymer-supporting PBCBD shows that it contains $2.41 \%$ of S element (CTA loading: $0.376 \mathrm{mmol} / \mathrm{g}$ ). The PBCBD was then used as a macro-RAFT agent to mediate RAFT polymerization of $4 \mathrm{VP}$ to produce P4VP brushes on the PVBCS nanosphere surfaces. The polymerizations ([4VP]:[PBCBD]: $[\mathrm{BCBD}]:[\mathrm{AIBN}]=2000: 6: 6: 1)$ were conducted in the presence of a free RAFT agent BCBD in 2-propanol at $50^{\circ} \mathrm{C}$ for different reaction times. The thickness of P4VP brushes grafted onto PVBCS nanosphere surfaces can be controlled by the polymerization time, as shown in Table 1. It can be seen from the table, an increase in thickness of grafted $\mathrm{P} 4 \mathrm{VP}$ shells from 0 to $3.5 \mathrm{~nm}$ is observed when the polymerization time increases from 0 to $24 \mathrm{~h}$, which indicates that the polymerization of $4 \mathrm{VP}$ can be well controlled under the present polymerization conditions. At the same time, the content of Pd on different thickness P4VP shells are also increased, which indicates that we can also control the content of Pd loading (from 0-10.1 wt\%) in the nanospheres by adjusting the polymerization time.

The chemical composition of the nanosphere surfaces at various stages was determined by XPS. Figure 2(a-c) shows the XPS wide scan, C 1s, and $\mathrm{Cl} 2 \mathrm{p}$ spectra of the PVBCS nanosphere surfaces. The peak components in $\mathrm{C} 1 \mathrm{~s}$ at the BEs of about 284.6 and $286.3 \mathrm{eV}$ are attributable to the $\underline{\mathrm{C}}-\mathrm{C} / \underline{\mathrm{C}}-\mathrm{H}$ and $\underline{\mathrm{C}}-\mathrm{Cl}$ species $[35,36]$, respectively. The $\mathrm{Cl} 2 \mathrm{p}$

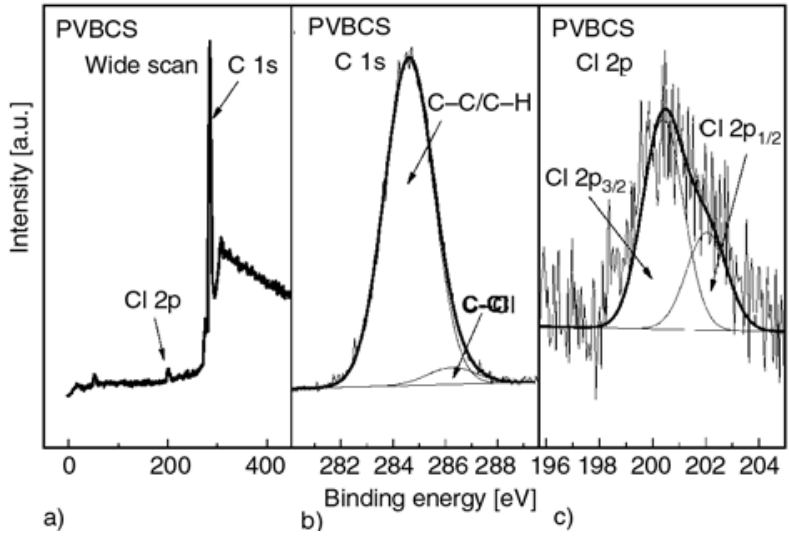

Figure 2. XPS a) wide scan, b) $\mathrm{C} 1 \mathrm{~s}$, and c) $\mathrm{Cl} 2 \mathrm{p}$ corelevel spectra of the PVBCS nanosphere surface

core-level spectrum consists of $\mathrm{Cl} 2 \mathrm{p}_{3 / 2}$ and $\mathrm{Cl} 2 \mathrm{p}_{1 / 2}$ doublet at the BEs of about 200.4 and $202.0 \mathrm{eV}$, respectively [35], attributable to the covalently bonded chlorine $(\mathrm{C}-\underline{\mathrm{Cl}})$ species.

Figure $3(\mathrm{a}-\mathrm{c})$ shows the XPS wide scan, $\mathrm{C} 1 \mathrm{~s}$ and $S 2 p$ spectra of the PBCBD nanosphere surfaces after surface modification of PVBCS. The XPS wide scan spectrum shows four peak component at the BEs of about 163, 200, 284 and $400 \mathrm{eV}$, attributable to $\mathrm{S} 2 \mathrm{p}, \mathrm{Cl} 2 \mathrm{p}, \mathrm{C}$ 1s and $\mathrm{N}$ 1s species of the PBCBD nanospheres, respectively. The peak components in $\mathrm{C} 1 \mathrm{~s}$ core-level spectrum at the BEs of about $284.6,284.9$ and $286.6 \mathrm{eV}$ are attributable to the $\underline{\mathrm{C}}-\mathrm{C} / \underline{\mathrm{C}}-\mathrm{H}, \underline{\mathrm{C}}-\mathrm{S} / \underline{\mathrm{C}}=\mathrm{S}$, and $\underline{\mathrm{C}}-\mathrm{Cl}$ species $[33$, 34], respectively. The $S 2 p$ core-level spectrum can be curve-fitted with two peak component with BEs at about 162.9 and $164.2 \mathrm{eV}$, attributable to the

Table 1. Chemical composition, diameter, and layer thickness of the PVBCS-1 nanospheres

\begin{tabular}{|c|c|c|c|c|c|}
\hline Entry & $\begin{array}{c}\text { Polymerization time } \\
{[\mathbf{h}]}\end{array}$ & $\begin{array}{c}\mathbf{N}^{\mathbf{b}} \\
{[\mathbf{w t} \%]}\end{array}$ & $\begin{array}{c}\text { Diameter }(\mathbf{D})^{\mathbf{c}} \\
{[\mathbf{n m}]}\end{array}$ & $\begin{array}{c}\text { Shell thickness } \\
{[\mathbf{n m}]}\end{array}$ & $\begin{array}{c}\text { Content of Pde }^{\mathbf{d}} \\
{\left[\mathbf{w t} \mathbf{\%}^{\mathbf{2}}\right]}\end{array}$ \\
\hline 1 & 0 & 0.00 & 70 & 0.0 & 0.0 \\
\hline 2 & 12 & 2.20 & 74 & 2.0 & 8.9 \\
\hline 3 & 15 & 2.44 & 75 & 2.5 & 9.9 \\
\hline 4 & 24 & 2.90 & 76 & 3.0 & 10.0 \\
\hline 5 & 36 & 3.43 & 77 & 3.5 & 10.1 \\
\hline
\end{tabular}

aPolymerization conditions: 4VP (3 ml), 2-propanol (10 ml, containing $0.2 \mathrm{~g}$ PBCBD), AIBN (2 mg), BCBD (0.074 mmol),

$[\mathrm{M}]:[\mathrm{PBCBD}]:[\mathrm{BCBD}]:[\mathrm{AIBN}]=2000: 6: 6: 1$, temperature $=50^{\circ} \mathrm{C}$

bPercentage of nitrogen of PVBCS-1 nanospheres, deduced from elemental analysis

'Diameter of the PVBCS-1, calculated from bulk nitrogen composition and according to Equation (1):

$D=\left[\frac{\left(\frac{D_{0}}{2}\right)^{3} \cdot 13.32 \%}{13.32 \%-\% N}\right]^{\frac{1}{3}} \cdot 2$

where $D_{0}$ is the diameter of the PVBCS $(70 \mathrm{~nm}) ; 13.32 \%$ is the theoretical wt $\%$ of nitrogen in P4VP; $\% N$ is the nitrogen composition in the sample.

dThickness of the P4VP shell in PVBCS-1

ePercentage of palladium in PVBCS-1 nanospheres, deduced from the atomic absorption spectroscopy (AAS) 


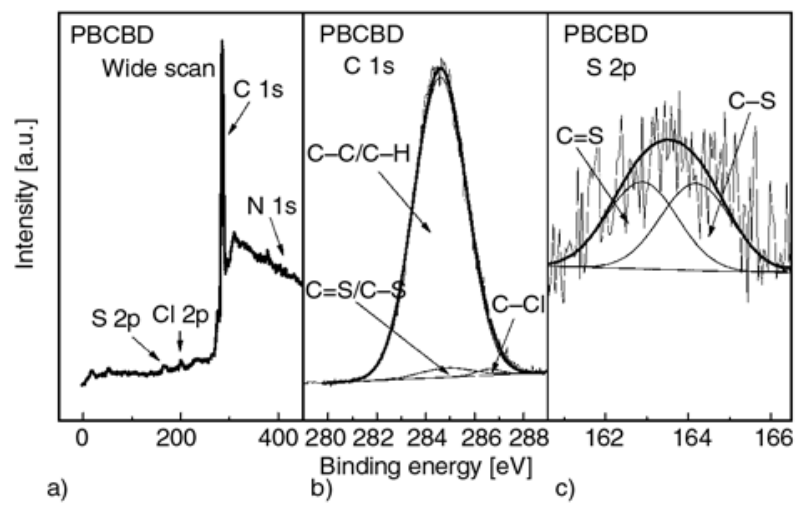

Figure 3. XPS a) wide scan, b) C 1s, and c) S 2p corelevel spectra of the PBCBD nanosphere surface

$\mathrm{C}=\underline{\mathrm{S}}$ and $\mathrm{C}-\underline{\mathrm{S}}$ species $[23,36]$, respectively. It is a key step that the immobilization of RAFT agent on the surfaces of PVBCS nanospheres for this work. Generally, the reaction of benzyl chloride group with carbazole and carbon sulfide is very active and the substitution efficiency of chlorine atoms was reported to be close to $100 \%[37,38]$. However, the chloride signal can still be discernible in the XPS wide scan spectrum, indicating that there are chlorine atoms in the range of the XPS probing. It is well known that the probing depth of the XPS technique is about $8 \mathrm{~nm}$ in an organic matrix [39]. In addition, the XPS-derived surface $[\mathrm{Cl}] /[\mathrm{C}]$ ratio of $1 / 100$ (after reaction) in PBCBD nanospheres is much lower than that of $1 / 20$ (before reaction) in PVBCS nanospheres, indicating that the most of the benzyl chloride groups have been transferred into the dithioester groups; at the same time, the thickness of CTA layer immobilized on the surfaces of PVBCS nanosphere should be less than $8 \mathrm{~nm}$. All these results demonstrated that the RAFT agent BCBD was successfully anchored onto the PVBCS nanosphere surfaces.

Figure $4(\mathrm{a}-\mathrm{c})$ shows the XPS wide scan, C 1s, and $\mathrm{N}$ 1s spectra of the surfaces of PVBCS-1 nanospheres obtained by the surface RAFT polymerization of $4 \mathrm{VP}$ for $24 \mathrm{~h}$ (as shown in entry 4 of Table 1). The XPS wide scan spectrum shows two dominant peak component at the BEs of about 284 and $400 \mathrm{eV}$, attributable to $\mathrm{C} 1 \mathrm{~s}$, and $\mathrm{N} 1 \mathrm{~s}$ species of the PVBCS-1 nanospheres, respectively. In addition, a sulfur signal is also discernable though it is weaker, as shown in Figure 4d. The C 1s core-level spectrum of the PVBCS- 1 surface can be curve-fitted into three peak components with BEs at 284.6,

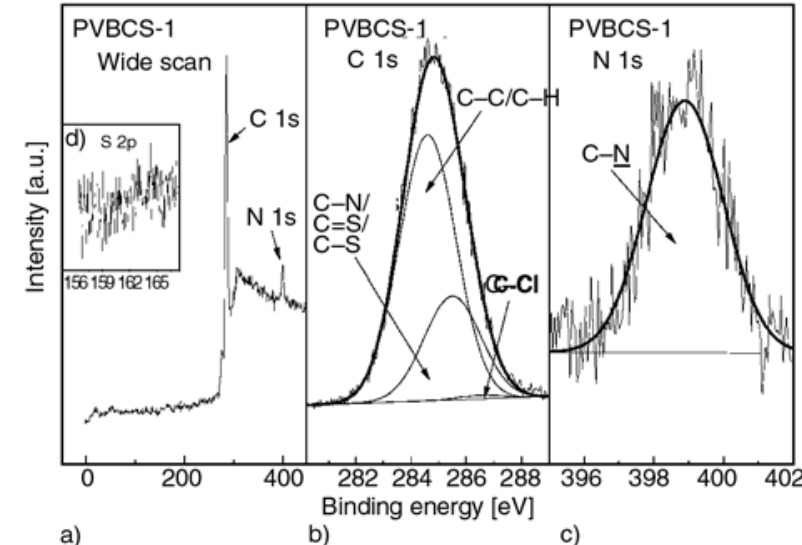

b)

Figure 4. XPS a) wide scan, b) C 1s, c) N 1s, and d) $S$ 2p core-level spectra of the P4VP-grafted PVBCS or PVBCS-1 nanosphere surface from $24 \mathrm{~h}$ of surface RAFT polymerization

285.5 , and $286.5 \mathrm{eV}$, attributable to the $\underline{\mathrm{C}}-\mathrm{C} / \underline{\mathrm{C}}-\mathrm{H}$, $\underline{\mathrm{C}}-\mathrm{N} / \underline{\mathrm{C}}=\mathrm{S} / \underline{\mathrm{C}}-\mathrm{S}$, and $\underline{\mathrm{C}}-\mathrm{Cl}$ species, respectively. The N 1s core-level spectrum shows a predominantly peak component at BEs of $398.9 \mathrm{eV}$, attributable to the imine moiety $(-\mathrm{N}=)$ of the pyridine rings [40]. The results indicate that the P4VP shells were successfully immobilized onto the PVBCS nanosphere surfaces.

Poly(vinylpyridine) is the most used polymer for nanoparticle stabilization because it fulfils ligand requirements [41]. In this work, the PVBCS-1 nanospheres were activated in the $\mathrm{PdCl}_{2}$ solution, and then hydrazine hydrate was used as the reducing agent for the $\mathrm{PdCl}_{2}$-activated nanospheres. The nanospheres gradually turned from light-yellow to black, indicating the formation of palladium metal nanoparticles in the P4VP shell (PVBCS-2). Figure 5(a-d) shows the XPS wide scan, C 1s, N 1s, and Pd 3d spectra of the PVBCS-2 nanosphere surfaces. The XPS wide scan shows five peak components at the BEs of about 162, 200, 284, 335, and $398 \mathrm{eV}$, attributable to $\mathrm{S} 2 \mathrm{p}, \mathrm{Cl} 2 \mathrm{p}, \mathrm{C} 1 \mathrm{~s}, \mathrm{Pd} 3 \mathrm{~d}$, and $\mathrm{N}$ 1s species, respectively. The $\mathrm{C} 1 \mathrm{~s}$ core-level spectrum of the PVBCS-2 surface can be curve-fitted into three peak components with BEs at about $284.6,285.5$, and $286.5 \mathrm{eV}$, attributable to the $\underline{\mathrm{C}}-\mathrm{C} / \underline{\mathrm{C}}-\mathrm{H}, \underline{\mathrm{C}}-\mathrm{N} / \underline{\mathrm{C}}-\mathrm{S} / \underline{\mathrm{C}}=\mathrm{S}$, and $\underline{\mathrm{C}}-\mathrm{Cl}$ species, respectively. The peak component at the BEs of $398.9 \mathrm{eV}$ in the $\mathrm{N} 1 \mathrm{~s}$ core-level spectrum is attributable to the imine moiety $(-\mathrm{N}=)$ of the pyridine rings. The XPS spectrum of Pd $3 \mathrm{~d}$ can be curve-fitted into two spin-orbit-split doublets, as illustrated in Figure 5d. The two peak components at the BEs 


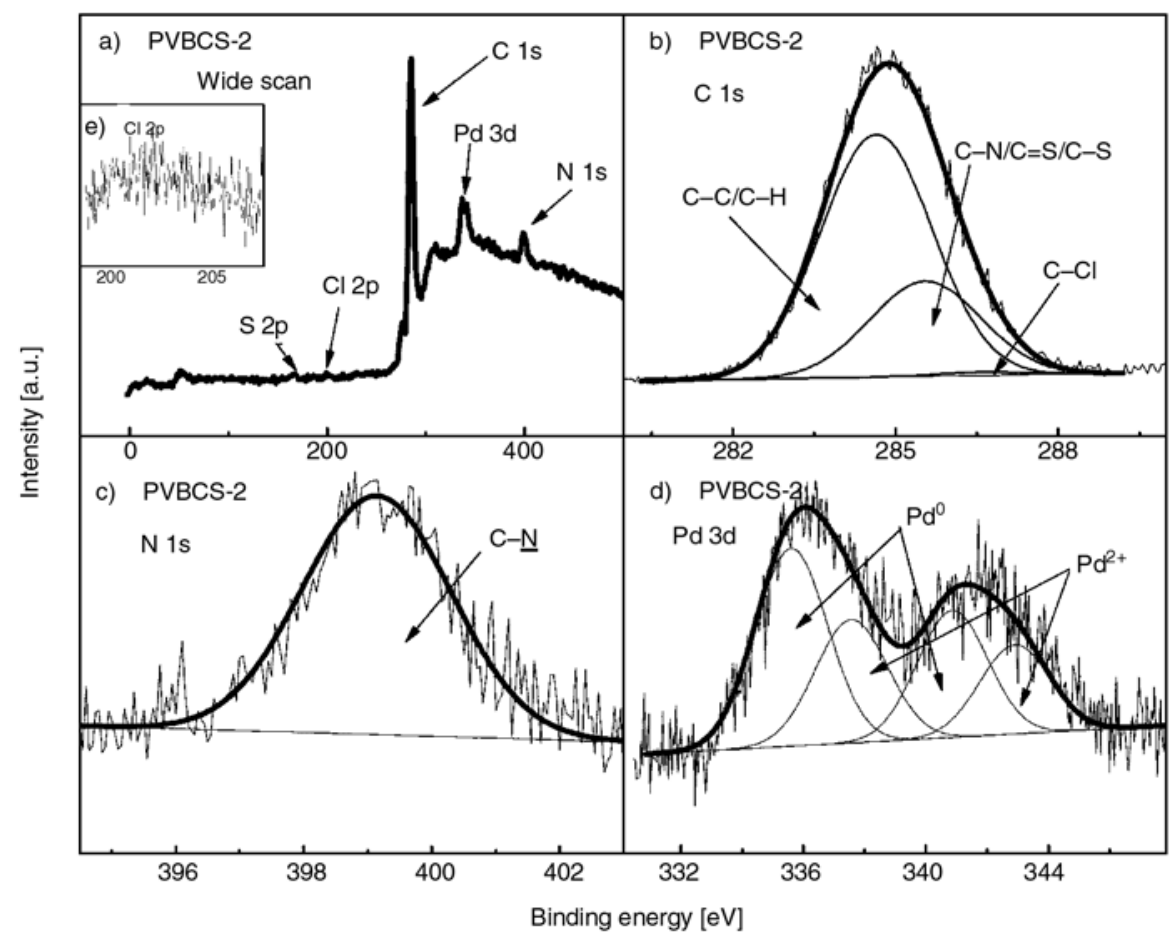

Figure 5. XPS a) wide scan, b) C 1s, c) N 1s, d) Pd 3d, and e) Cl 2p core-level of the Pd/P4VP composite shell nanosphere (PVBCS-2 nanosphere) surface

of about 335.4 and $340.7 \mathrm{eV}$ are attributable to the $\mathrm{Pd} 3 \mathrm{~d}_{5 / 2}$ and $\mathrm{Pd} 3 \mathrm{~d}_{3 / 2}$ species, which can be indexed to the $\mathrm{Pd}(0)$ state $[36,42]$. The other set of peaks at $337.7 \mathrm{eV}\left(\operatorname{Pd~} 3 \mathrm{~d}_{5 / 2}\right)$ and $342.9 \mathrm{eV}\left(\operatorname{Pd} 3 \mathrm{~d}_{3 / 2}\right)$ is ascribed to the $\mathrm{Pd}^{2+}[38,43]$. Calculating the integration areas of these two doublets using XPSPEAK software, it can be estimated that the atomic ratio of $\mathrm{Pd} / \mathrm{Pd}^{2+}$ was about 59:41. The oxidation form of $\mathrm{Pd}$ is possibly palladium oxide, which may result from the surface oxidation of palladium nanoparticles when they are exposed to air. A similar phenomenon was also reported by others [42, 43].

\subsection{Activity for the heck reaction of the PVBCS-2 nanospheres}

It is well-known that $\mathrm{Pd}$ is effective in catalyzing $\mathrm{C}-\mathrm{C}$ bond formation reactions [27-30]. Among palladium-catalyzed couplings, the Suzuki-Miyaura [29], Sonogashira [27] and Heck [28] reactions are the most widely used. In this work, the catalytic activity of the PVBCS-2 nanospheres for Heck reaction was investigated using the model reaction of iodobenzene and methyl acrylate (Figure 6). The reaction of iodobenzene (1.0 equiv) and methyl acrylate (1.5 equiv) with $15 \mathrm{mg}$ of PVBCS- 2 nanos-

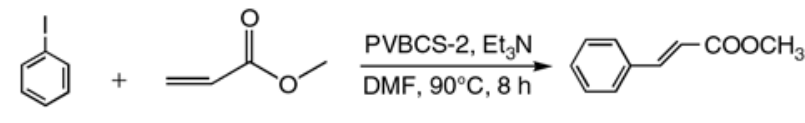

Figure 6. Schematic diagram illustrating Heck reaction using iodobenzene and methyl acrylate as the model reagents

pheres was performed at $90^{\circ} \mathrm{C}$ in DMF containing triethylamine (1.5 equiv). The results are listed in Table 2.

The freshly synthesized PVBCS-2 nanospheres exhibit a higher activity. Although the activity of the catalyst gradually decreases somewhat after subsequent recycling, the catalyst still shows a good activity even if it was used three times. XPS spectroscopy technique was also used to check the chemical composition of the recycled catalyst (PVBCS-2A) surfaces after being used four times. Figure 7(a-d) shows the XPS wide scan, C 1s,

Table 2. Results of Heck reaction catalyzed by PVBCS-2 nanosphere

\begin{tabular}{|c|c|c|c|c|}
\hline Run $^{\mathrm{a}}$ & 1 & 2 & 3 & 4 \\
\hline Isolated yield [\%] $^{\mathrm{b}}$ & 97 & 95 & 94 & 94 \\
\hline
\end{tabular}

aReaction performed with $5.0 \mathrm{mmol}$ of idobenzene, $7.5 \mathrm{mmol}$ of methyl acrylate, $7.5 \mathrm{mmol}$ of triethylamine, $20 \mathrm{ml}$ of DMF, PVBCS-2 (15 mg, Pd\% = 8.9 wt $\%$ )

bIsolated yield after filtration of crude reaction mixture on silica gel 


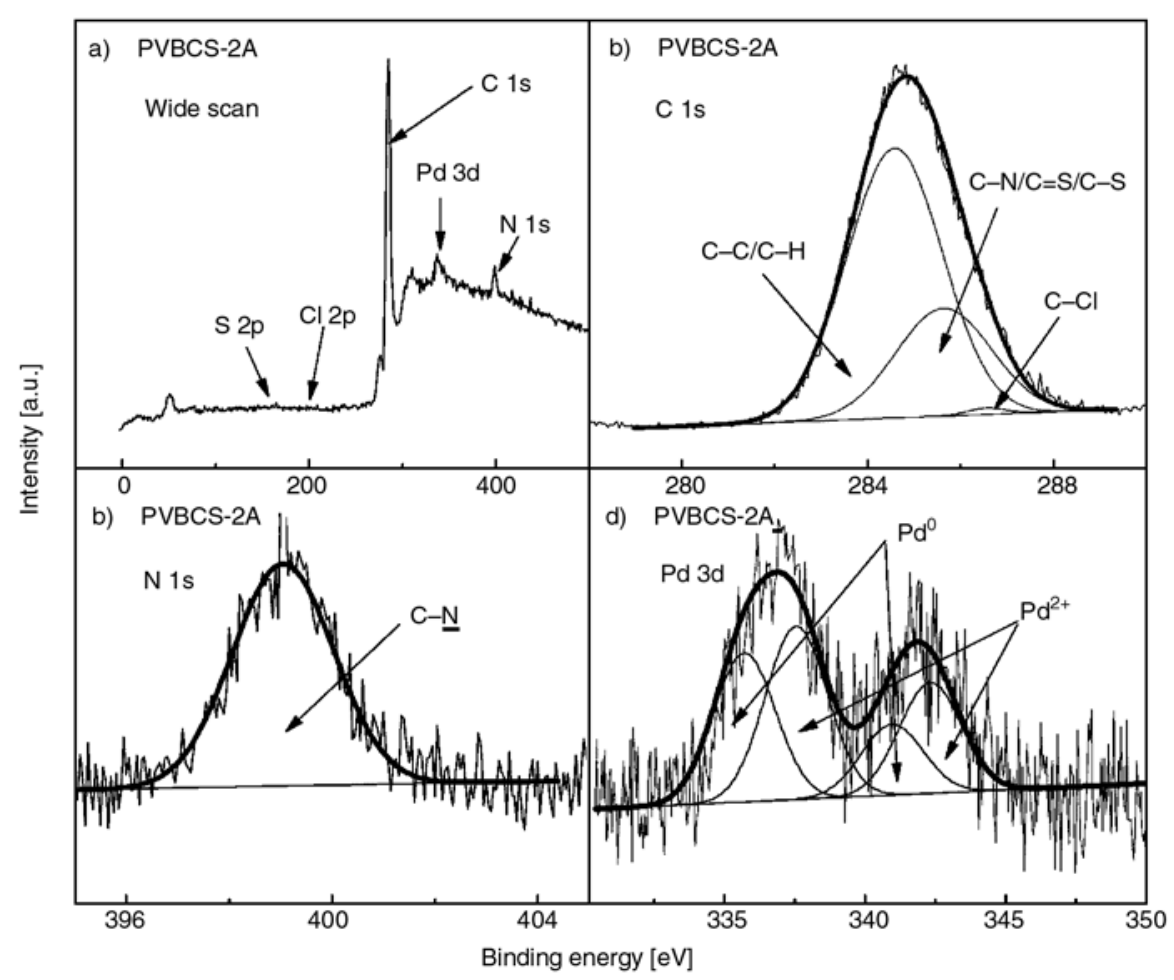

Figure 7. XPS a) Wide scan, b) C 1s, c) N 1s, and d) Pd 3d core-level spectra of the recycled PVBCS-2 nanophere (PVBCS-2A nanosphere) surface

$\mathrm{N} 1 \mathrm{~s}$, and Pd 3d spectra of the PVBCS-2A nanosphere surfaces. The XPS wide scan, $\mathrm{C} 1 \mathrm{~s}$, and $\mathrm{N}$ 1s spectra of the PVBCS-2A nanosphere surfaces have no significant changes as compared with the PVBCS-2 nanosphere surfaces. The XPS wide scan shows five peak components at the BEs of about $162,200,284,335$, and $398 \mathrm{eV}$, attributable to $\mathrm{S} 2 \mathrm{p}, \mathrm{Cl} 2 \mathrm{p}, \mathrm{C} 1 \mathrm{~s}, \mathrm{Pd} 3 \mathrm{~d}$, and $\mathrm{N} 1 \mathrm{~s}$ species, respectively. The $\mathrm{C} 1 \mathrm{~s}$ core-level spectrum of the PVBCS-2 surface can be curve-fitted into three peak components with BEs at about 284.6, 285.5, and $286.5 \mathrm{eV}$, attributable to the $\underline{\mathrm{C}}-\mathrm{C} / \underline{\mathrm{C}}-\mathrm{H}, \underline{\mathrm{C}}-\mathrm{N} /$ $\underline{\mathrm{C}}-\mathrm{S} / \underline{\mathrm{C}}=\mathrm{S}$, and $\underline{\mathrm{C}}-\mathrm{Cl}$ species, respectively. The peak component at the BEs of $398.9 \mathrm{eV}$ in the $\mathrm{N} 1 \mathrm{~s}$ core-level spectrum is attributable to the imine moiety $(-\mathrm{N}=)$ of the pyridine rings. As illustrated in Figure $7 \mathrm{~d}$, the doublet with a binding energy at $335.4 \mathrm{eV}\left(\operatorname{Pd} 3 \mathrm{~d}_{5 / 2}\right)$ and $340.7 \mathrm{eV}\left(\operatorname{Pd} 3 \mathrm{~d}_{3 / 2}\right)$ can be indexed to the $\mathrm{Pd}^{0}$. The other set of peaks at $337.6 \mathrm{eV}\left(\operatorname{Pd} 3 \mathrm{~d}_{5 / 2}\right)$ and $342.3 \mathrm{eV}\left(\operatorname{Pd} 3 \mathrm{~d}_{3 / 2}\right)$ is ascribed to the $\mathrm{Pd}^{2+}$. Different from the result of original PVBCS-2 nanospheres, the atomic ratio of $\mathrm{Pd}^{0} / \mathrm{Pd}^{2+}$ is about $33: 67$ by calculating the integration areas of these two doublets using XPSPEAK software after fours times catalytic cycles, being lower than the ratio $(59: 41)$ of the initial catalyst.
The increased oxidation form of $\mathrm{Pd}$ possibly results from the surface oxidation of palladium nanoparticles during the Heck reaction $[42,43]$.

\subsection{Morphology of the PVBCS nanospheres}

The morphologies of the PVBCS nanospheres at different stages of surface functionalization were observed by TEM. PVBCS nanospheres with an average diameter of about $70 \mathrm{~nm}$, as determined by TEM (Figure 8(a, b)), were obtained. After surface functionalization, the PVBCS-supporting chain transfer agent (PBCBD) was obtained, and the size and morphology of the nanospheres are almost identical to these of the PVBCS nanospheres (Figure $8 \mathrm{c}$ ). Figure $8 \mathrm{~d}$ shows the TEM image of the P4VP grafted PVBCS nanospheres (PVBCS-1) with a $76 \mathrm{~nm}$ of diameter after RAFT polymerization for $24 \mathrm{~h}$. Figure 8e shows the TEM images of the Pd/P4VP shell nanospheres (PVBCS-2). The small dark spots representing the palladium metal nanoparticles are dispersed throughout the surface of the PVBCS-2 nanospheres in the P4VP shell. The surface of the nanoparticles becomes a little rough after being recycled four times, as shown in Figure 8f. During the reaction process, most of the 

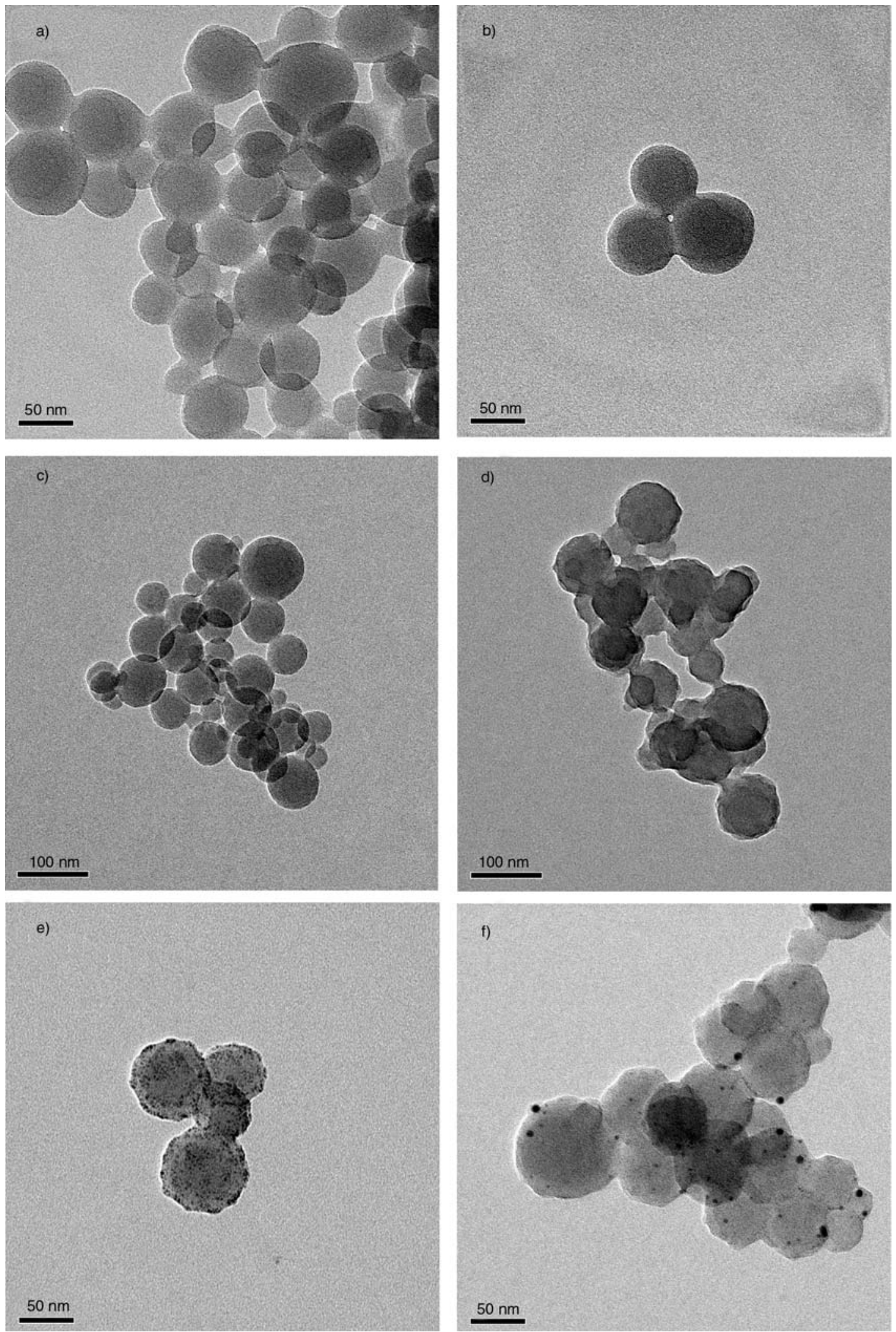

Figure 8. TEM images of a), b) the cross-linked PVBCS nanosphere, c) the PVBCS supporting chain transfer agent: PBCBD nanosphere, d) the PVBCS- $g$-P4VP nanosphere (PVBCS-1 nanosphere) obtained by the surface RAFT polymerization of 4VP for $24 \mathrm{~h}, \mathrm{e}$ ) the Pd/P4VP composite shell nanosphere (PVBCS-2 nanosphere), and f) the $\mathrm{Pd} / \mathrm{P} 4 \mathrm{VP}$ composite shell nanosphere (PVBCS-2A nanosphere) used in the Heck reaction after four times 
leached Pd species can be adsorbed on the polymer support [42], so the catalyst remains good in activity and is stable after being recycled several times.

\section{Conclusions}

A four-step method for preparing core-crosslinked polymer nanospheres with $\mathrm{Pd} / \mathrm{P} 4 \mathrm{VP}$ inorganic/ organic hybrid shells via RAFT polymerization was developed. This method allows the control over shell thickness by simply adjusting the RAFT polymerization time, and therefore the content of palladium. The Pd/P4VP shell nanospheres can serve as an efficient and reusable catalyst for the Heck reaction.

\section{Acknowledgements}

The financial supports of this work by the National Natural Science Foundation of China (Nos.20874069 and 50803044), the Science and Technology Development Planning of Jiangsu Province (Nos. BK2007702 and BK2007048), the International Cooperation Foundation of Jiangsu Province (No.BZ2007037), Pre-research Project of Soochow University, Program of Innovative Research Team of Suzhou University and Qing Lan Project are gratefully acknowledged.

\section{References}

[1] Caruso F.: Nanoengineering of particle surfaces. Advanced Materials, 13, 11-22 (2001). DOI: 10.1002/1521-4095(200101)13:1<11::AIDADMA11>3.0.CO;2-N

[2] Daniel M. C., Astruc. D.: Gold nanoparticles: Assembly, supramolecular chemistry, quantum-size-related properties, and applications toward biology, catalysis, and nanotechnology. Chemical Reviews, 104, 293346 (2004). DOI: $10.1021 / \mathrm{cr} 030698+$

[3] Du Y. J., Damron M., Tang G., Zheng H. X., Chu C-J., Osborne J. H.: Inorganic/organic hybrid coatings for aircraft aluminum alloy substrates. Progress in Organic Coatings, 41, 226-232 (2001). DOI: $10.1016 / \mathrm{S} 0300-9440(01) 00133-3$

[4] Lin C. K., Luo Y., You H., Quan Z., Zhang J., Fang J., Lin J.: Sol-gel-derived $\mathrm{BPO}_{4} / \mathrm{Ba}^{2+}$ as a new efficient and environmentally-friendly bluish-white luminescent material. Chemistry of Materials, 18, 458-464 (2006).

DOI: $\underline{10.1021 / \mathrm{cm} 052109 \mathrm{~h}}$
[5] Teng X., Shchukin D. G., Möhwald H.: Encapsulation of water-immiscible solvents in polyglutamate/polyelectrolyte nanocontainers. Advanced Functional Materials, 17, 1273-1278 (2007). DOI: $10.1002 /$ adfm.200601229

[6] Kim B-S., Taton T. A.: Multicomponent nanoparticles via self-assembly with cross-linked block copolymer surfactants. Langmuir, 23, 2198-2202 (2007). DOI: $\underline{10.1021 / \mathrm{la} 062692 \mathrm{w}}$

[7] Limpanart S., Khunthon S., Taepaiboon P., Supaphol P., Srikhirin T., Udomkichdecha W., Boontongkong Y.: Effect of the surfactant coverage on the preparation of polystyrene-clay nanocomposites prepared by melt intercalation. Materials Letters, 59, 2292-2295 (2005). DOI: $\underline{10.1016 / \text { j.matlet.2005.03.006 }}$

[8] Hu Q. Y., Hampsey J. E., Jiang N., Li C. J., Lu Y. F.: Surfactant-templated organic functionalized mesoporous silica with phosphino ligands. Chemistry of Materials, 17, 1561-1569 (2005). DOI: $\underline{10.1021 / \mathrm{cm} 0491983}$

[9] Otsu T., Yoshida M.: Role of initiator-transfer agentterminator (iniferter) in radical polymerizations: Polymer design by organic disulfides as iniferters. Die Makromolekulare Chemie, Rapid Communications, 3, 127-132 (1982).

DOI: $10.1002 /$ marc. 1982.030030208

[10] Wang J. S., Matyjaszewski K.: Controlled/'living' radical polymerization. Atom transfer radical polymerization in the presence of transition-metal complexes. Journal of the American Chemical Society, 117, 5614-5615 (1995). DOI: $\underline{10.1021 / \mathrm{ja} 00125 \mathrm{a} 035}$

[11] Chiefari J., Chong Y. K., Ercole F., Krstina J., Jeffery J., Le T. P. T., Mayadunne R. T. A., Meijs G. F., Moad C. L., Moad G., Rizzardo E., Thang S. H.: Living freeradical polymerization by reversible addition-fragmentation chain transfer: The RAFT process. Macromolecules, 31, 5559-5562 (1998).

DOI: $10.1021 / \mathrm{ma9804951}$

[12] Kasseh A., Ait-Kadi A., Riedl B., Pierson J. F.: Organic/inorganic hybrid composites prepared by polymerization compounding and controlled free radical polymerization. Polymer, 44, 1367-1375 (2003). DOI: $\underline{\text { 10.1016/S0032-3861(02)00905-9 }}$

[13] Fulghum T. M., Patton D. L., Advincula R. C.: Fuzzy ternary particle systems by surface-initiated atom transfer radical polymerization from layer-by-layer colloidal core-shell macroinitiator particles. Langmuir, 22, 8397-8402 (2006).

DOI: $10.1021 / \mathrm{la} 0601509$

[14] Lowe A. B., Sumerlin B. S., Donovan M. S., McCormick C. L.: Facile preparation of transition metal nanoparticles stabilized by well-defined (co)polymers synthesized via aqueous reversible addition-fragmentation chain transfer polymerization. Journal of the American Chemical Society, 124, 11562-11563 (2002). DOI: $\underline{10.1021 / \mathrm{ja} 020556 \mathrm{~h}}$ 
[15] Braunecker W. A., Matyjaszewski K.: Controlled/living radical polymerization: Features, developments, and perspectives. Progress in Polymer Science, 32, 93-146 (2007).

DOI: 10.1016/j.progpolymsci.2006.11.002

[16] Moad G., Rizzardo E., Thang S. H.: Radical additionfragmentation chemistry in polymer synthesis. Polymer, 49, 1079-1131 (2008).

DOI: $\underline{10.1016 / j . p o l y m e r .2007 .11 .020}$

[17] Lowe A. B., McCormick C. L.: Reversible additionfragmentation chain transfer (RAFT) radical polymerization and the synthesis of water-soluble (co)polymers under homogeneous conditions in organic and aqueous media. Progress in Polymer Science, 32, 283351 (2007)

DOI: 10.1016/j.progpolymsci.2006.11.003

[18] Guo T-Y., Liu P., Zhu J-W., Song M-D., Zhang B-H.: Well-defined lactose-containing polymer grafted onto silica particles. Biomacromolecules, 7, 1196-1202 (2006).

DOI: $10.1021 / \mathrm{bm} 051011 \mathrm{t}$

[19] Fustin C-A., Colard C., Filali M., Guillet P., Duwez A. S., Meier M. A. R., Schubert U. S., Gohy J-F.: Tuning the hydrophilicity of gold nanoparticles templated in star block copolymers. Langmuir, 22, 6690-6695 (2006).

DOI: $10.1021 / \mathrm{la} 060758 \mathrm{~h}$

[20] Skaff H., Emrick T.: Reversible addition fragmentation chain transfer (RAFT) polymerization from unprotected cadmium selenide nanoparticles. Angewandte Chemie, International Edition, 43, 5383-5386 (2004).

DOI: $10.1002 /$ anie. 200453822

[21] Hong C-Y., You Y-Z., Pan C-Y.: Synthesis of watersoluble multiwalled carbon nanotubes with grafted temperature-responsive shells by surface RAFT polymerization. Chemistry of Materials, 17, 2247-2254 (2005).

DOI: $10.1021 / \mathrm{cm} 0480541$

[22] Perrier S., Takolpuckdee P., Mars C. A.: Reversible addition-fragmentation chain transfer polymerization mediated by a solid supported chain transfer agent. Macromolecules, 38, 6770-6774 (2005). DOI: $10.1021 / \mathrm{ma} 0506886$

[23] Peng Q., Lai D. M. Y., Kang E. T., Neoh K. G.: Preparation of polymer-silicon(100) hybrids via interfaceinitiated reversible addition-fragmentation chaintransfer (RAFT) polymerization. Macromolecules, 39, 5577-5582 (2006).

DOI: $10.1021 / \mathrm{ma} 0607362$

[24] Pyun J., Matyjaszewski K.: Synthesis of nanocomposite organic/inorganic hybrid materials using controlled/'living' radical polymerization. Chemistry of Materials, 13, 3436-3448 (2001).

DOI: $10.1021 / \mathrm{cm} 011065 j$
[25] Nishi H., Kobatake S.: Photochromism and optical property of gold nanoparticles covered with low-polydispersity diarylethene polymers. Macromolecules, 41, 3995-4002 (2008).

DOI: $10.1021 / \mathrm{ma} 702882 \mathrm{t}$

[26] Hotchkiss J. W., Lowe A. B., Boyes S. G.: Surface modification of gold nanorods with polymers synthesized by reversible addition-fragmentation chain transfer polymerization. Chemistry of Materials, 19, 6-13 (2007).

DOI: $10.1021 / \mathrm{cm} 0622912$

[27] Kim J-H., Lee D-H., Jun B-H., Lee Y-S.: Copper-free Sonogashira cross-coupling reaction catalyzed by polymer-supported $N$-heterocyclic carbene palladium complex. Tetrahedron Letters, 48, 7079-7084 (2007). DOI: $\underline{10.1016 / j . t e t l e t .2007 .08 .015}$

[28] Beletskaya I. P., Khokhlov A. R., Tarasenko E. A., Tyurin V. S.: Palladium supported on poly $(N$-vinylimidazole) or poly ( $N$-vinylimidazole-co- $N$-vinylcaprolactam) as a new recyclable catalyst for the Mizoroki-Heck reaction. Journal of Organometallic Chemistry, 692, 4402-4406 (2007). DOI: 10.1016/j.jorganchem.2007.06.056

[29] Tzschucke C. C., Andrushko V., Bannwarth W.: Assessment of the reusability of Pd complexes supported on fluorous silica gel as catalysts for Suzuki couplings. European Journal of Organic Chemistry, 24, 5248-5261 (2005).

DOI: $\underline{10.1002 / \text { ejoc. } 200500281}$

[30] Drelinkiewicz A., Knapik A., Waksmundzka-Góra A., Bukowska A., Bukowski W., Noworól J.: Functional gel-type resin based palladium catalysts: The role of polymer properties in the hydrogenation of the $\mathrm{C}=\mathrm{C}$ bond of maleic and fumaric acids, the isomers of dicarboxylic acids. Reactive and Functional Polymers, 68, 1059-1071 (2008).

DOI: $10.1016 /$ j.reactfunctpolym.2008.02.008

[31] Fryling C. F., Harrington E. W.: Emulsion polymerization. Industrial and Engineering Chemistry, 36, 114-117 (1944).

DOI: $\underline{10.1021 / \mathrm{ie} 50410 \mathrm{a} 004}$

[32] Zhou D., Zhu X. L., Zhu J., Hu L. H., Cheng Z. P.: Influence of the chemical structure of dithiocarbamates with different $\mathrm{R}$ groups on the reversible addition-fragmentation chain transfer polymerization. Journal of Applied Polymer Science, 103, 982-988 (2007). DOI: 10.1002/app.25280

[33] Barner L., Li C. E., Hao X. J., Stenzel M. H., BarnerKowollik C., Davis T. P.: Synthesis of core-shell poly(divinylbenzene) microspheres via reversible addition fragmentation chain transfer graft polymerization of styrene. Journal of Polymer Science Part A: Polymer Chemistry, 42, 5067-5076 (2004). DOI: $\underline{10.1002 / \text { pola.20328 }}$ 
[34] Zhao Y., Perrier S.: Synthesis of well-defined homopolymer and diblock copolymer grafted onto silica particles by Z-supported RAFT polymerization. Macromolecules, 39, 8603-8608 (2006).

DOI: $10.1021 / \mathrm{ma} 061586 \mathrm{y}$

[35] Beamson G., Briggs D.: High-resolution XPS of organic polymers: The scienta ESCA300 Database. Wiley, Chichester (1992).

[36] Moulder J. F., Stickle W. F., Sobol P. E., Bomben K. D.: Handbook of X-ray photoelectron spectroscopy. Perkin-Elmer, Eden Prairie (1992).

[37] Quinn J. F., Chaplin R. P., Davis T. P.: Facile synthesis of comb, star, and graft polymers via reversible addition-fragmentation chain transfer (RAFT) polymerization. Journal of Polymer Science Part A: Polymer Chemistry, 40, 2956-2966 (2002).

DOI: $10.1002 /$ pola. 10369

[38] Wang S. M., Cheng Z. P., Zhu J., Zhang Z. B., Zhu X. L.: Synthesis of amphiphilic and thermosensitive graft copolymers with fluorescence P(St-co-(p-CMS))- $g$ PNIPAAM by combination of NMP and RAFT methods. Journal of Polymer Science Part A: Polymer Chemistry, 45, 5318-5328 (2007). DOI: $\underline{10.1002 / \text { pola. } 22277}$

[39] Briggs D.: Surface analysis of polymers by XPS and static SIMS. Cambridge University Press, New York (1998).
[40] Cheng Z. P., Zhang L. F., Zhu X. L., Kang E. T., Neoh K. G.: Organic/inorganic hybrid nanospheres coated with palladium/P4VP shells from surface-initiated atom transfer radical polymerization. Journal of Polymer Science Part A: Polymer Chemistry, 46, 2119 2131 (2008).

DOI: $10.1002 /$ pola. 22547

[41] Mathew J. P., Srinivasan M.: Photoelectron spectroscopy (XPS) studies on some palladium catalysts. European Polymer Journal, 31, 835-839 (1995).

DOI: 10.1016/0014-3057(95)00027-5

[42] Miao S., Zhang C., Liu Z., Han B., Xie Y., Ding S., Yang Z.: Highly efficient nanocatalysts supported on hollow polymer nanospheres: Synthesis, characterization, and applications. The Journal of Physical Chemistry C, 112, 774-780 (2008).

DOI: $10.1021 / \mathrm{jp} 076596 \mathrm{v}$

[43] Choudary B. M., Madhi S., Chowdari N. S., Kantam M. L., Sreedhar B.: Layered double hydroxide supported nanopalladium catalyst for Heck-, Suzuki-, Sonogashira-, and Stille-type coupling reactions of chloroarenes. Journal of the American Chemical Society, 124, 14127-14136 (2002).

DOI: $10.1021 / \mathrm{ja} 026975 \mathrm{w}$ 